\title{
DIAGNÓSTICO DE CANTEIROS DE OBRAS SITUADOS NA CONURBAÇÃO CRAJUBAR NO CARIRI CEARENSE
}

\author{
Diagnosis of construction sites situated in the Crajubar \\ Conurbation in the Cariri Cearense
}

\author{
Antônio Italcy de Oliveira Júnior ${ }^{1}$, Michelly Matos Pereira ${ }^{2}$, Celme Torres Ferreira da Costa ${ }^{3}$ \\ Recebido em 16 de fevereiro de 2017; aceito em 18 de julho de 2017; disponível on-line em 03 de abril de 2018.
}

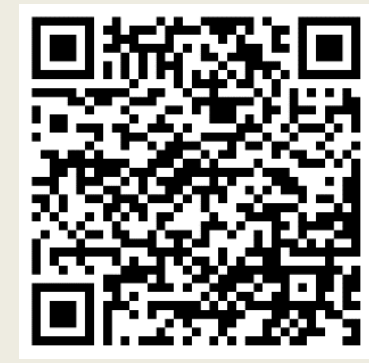

PALAVRAS CHAVE:

Produção Civil;

Gerenciamento de obras;

Planejamento de Canteiro de obras;

Construção civil

Crajubar;

\section{KEYWORDS:}

Civil Production;

Construction

management;

Construction Site

Planning;

Civil Construction;

Crajubar;

\begin{abstract}
RESUMO: No momento de instabilidade econômica em que se encontra o país, ações que minimizem os gastos e que aumentem a produtividade na construção civil visando ao desenvolvimento sustentável dos meios de produção estão cada vez mais sendo solicitadas. Com o intuito de realizar um diagnóstico da disposição, organização e práticas nos canteiros de obra da região do Crajubar, foram estudadas dez construções em execução na região. A amostra selecionada contemplava edificações horizontais e verticais, com finalidade de uso comercial, residencial e mista. Os dados foram obtidos a partir do método de diagnóstico que consiste na aplicação de uma lista de verificação (check-list) padronizada, que contemplava três grupos a serem analisados: instalações provisórias, segurança na obra e movimentação e armazenagem de materiais. Para a visualização e identificação de falhas nos canteiros foi feito um registro fotográfico de itens pré-determinados. De posse das informações coletadas foram atribuídas notas para os grupos, calculada a nota global (que é a média aritmética das notas de grupo) e as obras foram distribuídas em quatro categorias: ótimas, boas, regulares e ruins. As obras horizontais obtiveram as piores notas, entre 4,01 e 6, enquanto as obras verticais que apresentavam políticas de gestão de qualidade se destacaram com as melhores notas, entre 8,01 e 10. O tipo de obra foi o fator que mais influenciou na qualidade dos canteiros de obras avaliados no Crajubar cearense.
\end{abstract}

ABSTRACT: At a time of economic instability in the country, actions that minimize expenditures and increase productivity in civil construction aimed at the sustainable development of the means of production are increasingly being requested. In order to make a diagnosis of the layout, organization and practices in the construction sites of the Crajubar region, ten constructions were studied in the region. The sample selected included horizontal and vertical buildings, for commercial, residential and mixed use. The data were obtained from the diagnostic method, which consists of the application of a standardized checklist, which included three groups to be analyzed: temporary installations, handling and storage of materials. Along with this list, a photographic record of predetermined items was made for the visualization and identification of defects in the construction. From the information collected, the group notes and a global grade (the arithmetic mean of the group notes) were assigned and the works were distributed into four categories: great, good, regular and bad. The horizontal construction obtained the worse notes, between 4.01 and 6 , while the vertical construction that presented policies of quality management stood out with the best notes, between 8,01 and 10. The type of construction was the factor that most influenced the quality of the construction sites evaluated in Crajubar cearense.

\footnotetext{
* Contato com os autores:

${ }^{1}$ e-mail: antonioitalcy@notmail.com (A. I. de Oliveira Júnior )

Eng. Civil, Mestrando do Programa de Pós-Graduação em Engenharia Civil da Universidade Federal de Pernambuco.

2e-mail: michellymatosp@gmail.com (M. M. Pereira )

Enga. Civil, Especialização em Docência do ensino superior pela Faculdade de Juazeiro do Norte, Professora do Curso de Arquitetura da Faculdade de Juazeiro do Norte.

${ }^{3}$ e-mail: celme.torres@ufca.edu.br (C. T. F. da Costa )

Enga. Civil, Doutora em Engenharia Civil pela Universidade Federal do Ceará, Professora do Curso de Engenharia Civil e do

Programa de Pós-Graduação em Desenvolvimento Regional Sustentável da Universidade Federal do Cariri.
} 


\section{INTRODUÇÃO}

As diversas atividades relacionadas à construção civil que geram impactos ao meio ambiente estão tendo nos últimos anos cada vez mais discussões e debates em vários meios de comunicação na comunidade científica. As práticas relacionadas à sustentabilidade, frequentemente, não são adotadas pela indústria da construção civil. Geralmente, devido à falta de informações e quantificação dos malefícios gerados durante processo construtivo das obras, além de existir uma resistência cultural a mudanças neste setor, conforme afirmam Mattana e Librelotto (2017).

É notório que a construção civil tem influenciado positivamente o cenário econômico nacional nas últimas décadas, gerando o aumento dos recursos financeiros do país. No entanto, a indústria da construção civil brasileira é muitas vezes destacada como um setor atrasado, de baixa produtividade e de elevados desperdícios de recursos. Isso é evidenciado, por exemplo, no grande desperdício de materiais nos canteiros de obra, como mostram diversos pesquisadores em seus estudos (MAGALHÃES, DANILEVICZ e SAURIN, 2017; NUNES, MAHLER e VALLE; 2009; FORMOSO et al., 2002; SOUZA, AGOPYAN e PALIARI, 1999). Muitos são os motivos pelos quais a construção civil carrega esse estigma.

Esse cenário evidencia o desafio que as empresas de construções encontram no que se refere à implantação de um modelo e métodos construtivos que visam a alcançar um desenvolvimento sustentável. 0 gerenciamento do canteiro de obras, por exemplo, é uma das atividades mais negligenciadas nesse contexto.

Uma atividade que poderia otimizar os recursos humanos empregados, reduzir desperdícios de materiais, diminuir gastos e garantir melhoria da qualidade final do produto (seja este uma edificação, uma obra de arte ou de infraestrutura) seria o exercício de se pensar no planejamento do canteiro de obras. Essa prática é defendida por pesquisadores, como Saurin e
Formoso (2006), que desenvolveram um trabalho de padronização de avaliação e planejamento de canteiro em obras no Rio Grande do Sul.

Apesar do crescimento socioeconômico nos últimos anos na área da construção civil, atualmente o país aponta para um momento de reflexão e, mais do que nunca, de planejamento para o setor. Nesses momentos é importante repensar sobre as práticas construtivas de gestão, mais do que nunca os conceitos de sustentabilidade devem ser considerados para solucionar os problemas do setor, e assim, otimizar os processos e reduzir os gastos utilizando a menor quantidade de recursos naturais possíveis (SCHRAMM e FORMOSO, 2015).

Concomitante a essa deflexão econômica, identificou-se na região do Cariri cearense uma carência por estudos capazes de apontar uma análise da qualidade de seus canteiros de obras, sobretudo nos municípios de Barbalha, Crato e Juazeiro do Norte em que o setor da construção civil é mais presente. Além disto, algumas questões surgem no que diz respeito ao planejamento, projeto e gerenciamento de canteiros visando ao desenvolvimento sustentável do setor. Por exemplo, como o tipo de obra, a finalidade da construção e a etapa de execução podem influenciar na qualidade dos canteiros de obras?

As respostas para estas questões consistem nas contribuições deste trabalho, tendo em vista que a organização e o planejamento do canteiro de obras refletem diretamente no andamento da obra, na saúde ocupacional do trabalhador, no impacto ambiental causado. Tornase relevante uma abordagem padronizada que possa refletir a qualidade das instalações dos canteiros, sua segurança aos colaboradores e as condições de operação e armazenamento de materiais. A partir dessa análise, o setor poderá ter indicativos de quais aspectos necessitam de implantação de melhorias nos seus canteiros, aumentando a qualidade do seu serviço e produto final, além de eliminar gastos muitas vezes gerados 
pelo desperdício de recursos e todos os valores que um modelo sustentável possibilita agregar a qualquer atividade produtiva.

Esta pesquisa teve por objetivo avaliar a qualidade dos canteiros de obra situados nos municípios de Barbalha, Crato e Juazeiro do Norte, situados na região do Cariri cearense, utilizando obras de diferentes finalidades, etapa de execução e porte, através da avaliação das instalações provisórias, segurança no trabalho, saúde ocupacional e sistemas de movimentação e armazenagem de materiais nos canteiros de obras.

\section{DESENVOLVIMENTO}

\section{1 ÁREA DE ESTUDO}

A região metropolitana do Cariri (RMC) encontra-se no sul do estado do Ceará, e sua localização pode ser visualizada na Figura 1. A mesma surgiu a partir da conurbação entre os municípios de Juazeiro do Norte, Crato e Barbalha (Crajubar) - denominado de triângulo Caririense (GURGEL, 2012). É composta além do Crajubar pelos municípios de Caririaçu, Farias Brito, Jardim, Missão Velha, Nova Olinda e Santana do Cariri.

A cidade de Barbalha dista $553 \mathrm{~km}$ da capital do estado, com uma altitude de $415 \mathrm{~m}$ acima do nível do mar, possui uma área é de $569,51 \mathrm{~km}^{2}$, tem uma população de 55.533 habitantes, está localizada no sopé da Chapada do Araripe e PIB equivalente a $\mathrm{R} \$ 455.763,00$ (IBGE, 2015a).

A cidade de Crato localiza-se a $505 \mathrm{~km}$ da capital, e a uma altitude de $446 \mathrm{~m}$ acima do nível do mar, também está situada no sopé da Chapada do Araripe e possui uma área de 1.009 km². Em 2013 tinha cerca de 126.591 habitantes e PIB igual a $\mathrm{R} \$ 932.173,00$ (IBGE, 2015b).

A cidade de Juazeiro do Norte fica a $491 \mathrm{~km}$ da capital Fortaleza, e a uma altitude de 377 m acima do nível do mar. Com uma área de $249 \mathrm{~km}^{2}$, Juazeiro do Norte é a menor das três cidades que compõem o Crajubar, sua população é de 266.022 habitantes, segundo a estimativa do IBGE (2015c), com uma taxa de urbanização de $95,3 \%$ e o produto interno bruto (PIB) correspondente a $\mathrm{R} \$ 1.966 .331,00$.

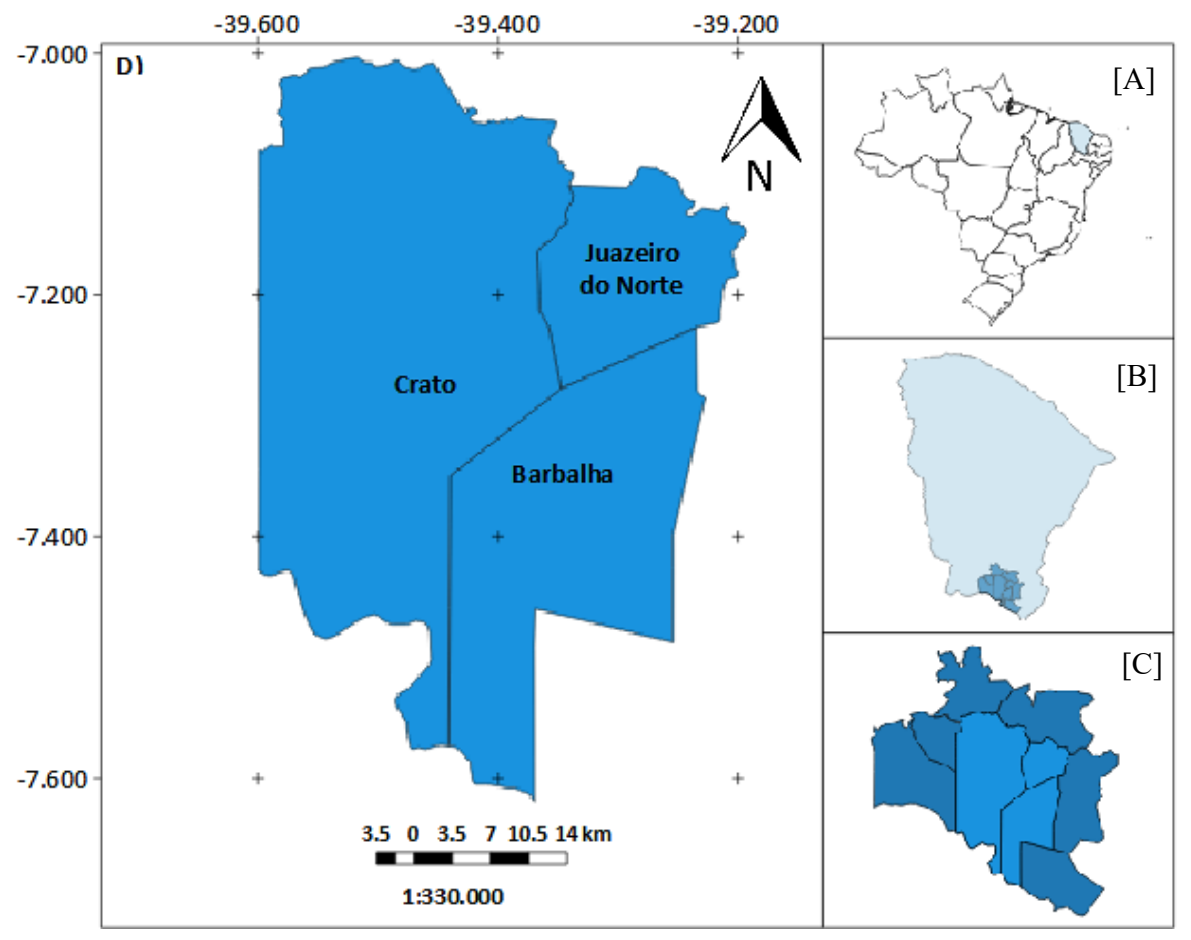

FIGURA 1: Área de estudo (Barbalha, Crato e Juazeiro do Norte). Em [A], o mapa do Brasil, com destaque para o Estado do Ceará; em [B] o mapa do Ceará, com destaque para a Região Metropolitana do Cariri; em [C] o mapa da Região Metropolitana do Cariri, com destaque para o Crajubar; e em D) o mapa do Crajubar, com destaque para os limites municipais entre Crato, Juazeiro do Norte e Barbalha. 
De acordo com Santos e Lima Júnior (2013), o Crajubar possui um número de empregos criados equivalente a 2380 somente pela indústria da construção civil no ano de 2010 e o número de estabelecimentos industriais na construção civil para o mesmo ano corresponde a 142. Já segundo Lima Júnior e Morais (2009) o produto interno bruto (PIB) municipal da indústria da construção civil dos três municípios juntos correspondia a mais $\mathrm{R} \$ 33.526,27$ mil reais no ano 1990 representando cerca de $40 \%$ do PIB total. Esses dados indicam a forte influência do setor da construção civil no histórico de desenvolvimento regional do Crajubar, embora vale ressaltar que o principal setor econômico da região são as indústrias de transformação.

Para Santos e Lima Júnior (2013), o evidente crescimento da construção civil no Crajubar, principalmente em Juazeiro do Norte, está associado à especulação imobiliária oriunda dos investimentos públicos em infraestrutura e melhorias de serviços disponibilizados na região, tais como, a construção do Hospital Regional do Cariri, espaços para eventos, centrais de abastecimentos, construção de escolas técnicas profissionalizantes e instituições de ensino superior, como o campus avançado da Universidade Federal do Ceará no ano de 2006, atualmente Universidade Federal do Cariri.

Além disso, o turismo no Crajubar tem tido um crescimento significativo e isso tem gerado a construção de novos serviços de hotelaria, principalmente em Juazeiro do Norte. Para Rodrigues et al. (2016) embora Juazeiro do Norte possua o menor território, dentre os municípios do Crajubar, é aquele que apresenta maior destaque em termo de desenvolvimento local.

\subsection{CARACTERIZAÇÃO DOS CANTEIROS DE OBRAS ANALISADOS}

Foram realizadas visitas de campo em dez obras na Região Metropolitana do Cariri cearense, mais precisamente na conurbação entre os municípios de Crato, Juazeiro do Norte e Barbalha (Crajubar). As visitas técnicas foram realizadas no período de agosto a outubro de 2015.

As obras selecionadas foram empreendimentos de edificações privadas, as quais estão apresentadas no Quadro 1, porém, suas identificações foram mantidas em sigilo, mediante solicitação dos gestores das mesmas. Algumas construtoras permitiram a verificação em mais de uma obra, portanto, foram verificadas 10 obras de 8 construtoras. Todas as obras verticais verificadas foram prédios com mais de 10 pavimentos e as obras horizontais foram residências unifamiliares térreas.

Além da identificação das obras, o Quadro 1 apresenta outras informações, como o tipo de obra (se vertical, horizontal, residencial, comercial, mista - residencial e comercial), cidade onde se localiza a obra e a fase em que cada obra estava quando foram realizadas as visitas técnicas.

A escolha das obras em diferentes fases executivas foi feita da forma mais diversificada possível, para que pudessem ser verificadas as influências da etapa da obra na qualidade dos canteiros. Essa mesma filosofia foi utilizada na escolha quanto ao tipo de obra, pois é sabido que a dinâmica de uma obra vertical difere de uma obra horizontal, principalmente do ponto de vista das etapas de execução.

\subsection{OBTENÇÃO E PROCEDIMENTOS DE ANÁLISES DOS DADOS}

Os dados foram obtidos a partir do método de diagnóstico que consiste na aplicação de uma lista de verificação (check-list) padronizada. A lista de verificação utilizada neste trabalho foi desenvolvida por Saurin e Formoso (2006) para o Programa de Tecnologia da Habitação.

A aplicação do check-list foi realizada in loco durante as visitas às obras analisadas. A mesma contempla mais de 120 itens para verificação distribuídos em três grupos: instalações provisórias (Grupo 1), segurança no trabalho (Grupo 2) e sistema de movimentação e armazenamento de materiais (Grupo 3).

Cada item da lista de verificação, de qualquer grupo, possui valor igual a 1 ponto. $O$ item recebe o ponto caso esteja assinalada a opção "sim". Existe uma tabela na lista de verificação, ao final de cada grupo, onde devem ser anotados os pontos obtidos (PO), os pontos possíveis (PP) e o índice do grupo (Ig), que é dado pela Equação (1). 


\begin{tabular}{|c|c|c|c|c|c|}
\hline $\begin{array}{c}\text { Identificação } \\
\text { da Obra }\end{array}$ & $\begin{array}{c}\text { Identificação } \\
\text { Construtora }\end{array}$ & Tipo de Obra & $\begin{array}{l}\text { Quantidade de } \\
\text { Edificações }\end{array}$ & Fase da Obra & Cidade da Obra \\
\hline Obra 1 & Const. A & Vertical, Mista & 2 & $\begin{array}{c}\text { Instalações (Torre } 1 \text { e } \\
\text { 2) }\end{array}$ & Juazeiro do Norte \\
\hline Obra 2 & Const. B & Vertical, Mista & 2 & \begin{tabular}{|c|} 
Vedações (Torre 1) e \\
Revestimento (Torre 2)
\end{tabular} & Juazeiro do Norte \\
\hline Obra 3 & Const. C & Vertical, Mista & 2 & $\begin{array}{c}\text { Estruturas (Torre 1) e } \\
\text { Vedação e Instalações } \\
\text { (Torre 2) }\end{array}$ & Juazeiro do Norte \\
\hline Obra 4 & Const. D & $\begin{array}{c}\text { Vertical, } \\
\text { Residencial }\end{array}$ & 1 & $\begin{array}{l}\text { Instalações e } \\
\text { Acabamentos }\end{array}$ & Juazeiro do Norte \\
\hline Obra 5 & Const. E & $\begin{array}{l}\text { Horizontal, } \\
\text { Residencial }\end{array}$ & 1 & Vedações & Barbalha \\
\hline Obra 6 & Const. D & Vertical, Mista & 1 & Fundações & Juazeiro do Norte \\
\hline Obra 7 & Const. F & $\begin{array}{l}\text { Horizontal, } \\
\text { Residencial }\end{array}$ & 1 & Acabamento & Barbalha \\
\hline Obra 8 & Const. C & Vertical, Comercial & 3 & $\begin{array}{c}\text { Estruturas (Torre 1 e 2) } \\
\text { e Vedação e } \\
\text { Instalações (Torre 3) }\end{array}$ & Crato \\
\hline Obra 9 & Const. G & $\begin{array}{l}\text { Horizontal, } \\
\text { Residencial }\end{array}$ & 1 & $\begin{array}{l}\text { Execução do Telhado e } \\
\text { Piso no Térreo }\end{array}$ & Barbalha \\
\hline Obra 10 & Const. H & $\begin{array}{c}\text { Vertical, } \\
\text { Residencial }\end{array}$ & 3 & $\begin{array}{c}\text { Acabamento (Torre 1) } \\
\text { Fundações (Torre 2) } \\
\text { Torre } 3 \text { não havia sido } \\
\text { iniciada. }\end{array}$ & Juazeiro do Norte \\
\hline
\end{tabular}

FONTE: Os autores

$$
I_{g}=\frac{P O}{P P} * 10
$$

Os pontos obtidos correspondem ao total de itens com avaliação positiva ("sim"), enquanto os pontos possíveis correspondem ao total de itens com avaliação positiva ou negativa, ou seja, o total de itens que puderam ser analisados. Os itens que não puderam passar por análise, por qualquer motivo, têm a marcação na coluna "não se aplica", e, portanto, não são considerados como pontos possíveis. Já o índice global do canteiro é calculado fazendo-se a média aritmética das notas dos três grupos.

Após o preenchimento das listas de verificação para cada obra foi realizada a tabulação das informações e para o cálculo das notas dos grupos de cada obra foi realizado com auxílio de uma planilha eletrônica. Em seguida foi calculada a estatística descritiva dos dados: valores máximos e mínimos, média aritmética, mediana, variância, desvio padrão e coeficiente de variação para cada grupo de itens da lista de verificação.
As notas obtidas foram analisadas de acordo com o Ministério do Trabalho e Emprego (BRASIL, 2003) que possui um sistema de classificação destes índices conforme mostrado no Quadro 2. A classificação "Péssimo" é atribuída a canteiros de obras em total desacordo com as normas regulamentadoras do trabalho, sendo necessária adequação as mesmas para que a obra possa continuar em funcionamento. A classificação "Ruim" é atribuída aos canteiros de obras que apresentam a maioria dos seus itens em desacordo com as normas regulamentadoras do trabalho, sendo necessário também adequação as mesmas para manter o funcionamento da obra. Nas classificações "Regular", "Bom" e "Ótimo", a maioria dos itens do canteiro atendem aos requisitos mínimos das normas regulamentadores do trabalho, não acarretando em paralisações nas obras, sendo a classificação atribuída de acordo com o maior ou menor percentual de itens em acordo com os padrões mínimos para funcionamento da obra. 


\begin{tabular}{|c|c|}
\hline QUADRO 2: Sistema de classificação segundo o Ministério do Trabalho e Emprego. \\
\hline Pontuação & Classificação \\
\hline $0-2$ & Péssimo \\
\hline $2,01-4$ & Ruim \\
\hline $4,01-6$ & Regular \\
\hline $6,01-8$ & Bom \\
\hline $8,01-10$ & Ótimo \\
\hline & FONTE: Brasil (2003).
\end{tabular}

\section{RESULTADOS E DISCUSSÕES}

Na Tabela 1 são apresentados os valores da análise estatística descritiva e os resultados obtidos com a aplicação do check-list em cada canteiro visitado.

\begin{tabular}{|c|c|c|c|c|c|c|c|c|c|}
\hline \multirow{2}{*}{ OBRA } & \multicolumn{3}{|c|}{ G1- Instalações Provisórias } & \multicolumn{3}{|c|}{ G2- Segurança na Obra } & \multicolumn{3}{|c|}{ G3 - Mov. Arm. Materiais } \\
\hline & PP & PO & Ig & PP & PO & Ig & PP & PO & Ig \\
\hline 1 & 35,00 & 29,00 & 8,29 & 37,00 & 31,00 & 8,38 & 32,00 & 25,00 & 7,81 \\
\hline 2 & 35,00 & 27,00 & 7,71 & 41,00 & 33,00 & 8,05 & 39,00 & 29,00 & 7,44 \\
\hline 3 & 35,00 & 30,00 & 8,57 & 41,00 & 33,00 & 8,05 & 39,00 & 29,00 & 7,44 \\
\hline 4 & 40,00 & 34,00 & 8,50 & 42,00 & 38,00 & 9,05 & 39,00 & 31,00 & 7,95 \\
\hline 5 & 31,00 & 16,00 & 5,16 & 14,00 & 9,00 & 6,43 & 24,00 & 10,00 & 4,17 \\
\hline 6 & 34,00 & 30,00 & 8,82 & 31,00 & 31,00 & 10,00 & 34,00 & 30,00 & 8,82 \\
\hline 7 & 15,00 & 5,00 & 3,33 & 13,00 & 7,00 & 5,38 & 27,00 & 10,00 & 3,70 \\
\hline 8 & 37,00 & 30,00 & 8,11 & 42,00 & 37,00 & 8,81 & 39,00 & 34,00 & 8,72 \\
\hline 9 & 31,00 & 18,00 & 5,81 & 16,00 & 9,00 & 5,63 & 24,00 & 10,00 & 4,17 \\
\hline 10 & 34,00 & 24,00 & 7,06 & 31,00 & 31,00 & 10,00 & 34,00 & 30,00 & 8,82 \\
\hline \multicolumn{3}{|c|}{ Máximo } & 8,82 & \multicolumn{2}{|c|}{ Máximo } & 10,00 & \multicolumn{2}{|c|}{ Máximo } & 8,82 \\
\hline \multicolumn{3}{|c|}{ Mínimo } & 3,33 & \multicolumn{2}{|c|}{ Mínimo } & 5,38 & \multicolumn{2}{|c|}{ Mínimo } & 3,70 \\
\hline \multicolumn{3}{|c|}{ Média } & 7,14 & \multicolumn{2}{|c|}{ Média } & 7,98 & \multicolumn{2}{|c|}{ Média } & 6,90 \\
\hline \multicolumn{3}{|c|}{ Mediana } & 7,91 & \multicolumn{2}{|c|}{ Mediana } & 8,21 & \multicolumn{2}{|c|}{ Mediana } & 8,09 \\
\hline \multicolumn{3}{|c|}{ Variância } & 3,28 & \multicolumn{2}{|c|}{ Variância } & 2,76 & \multicolumn{2}{|c|}{ Variância } & 3,16 \\
\hline \multicolumn{3}{|c|}{ Desvio Padrão } & 1,81 & \multicolumn{2}{|c|}{ Desvio Padrão } & 1,66 & \multicolumn{2}{|c|}{ Desvio Padrão } & 1,78 \\
\hline \multicolumn{3}{|c|}{ C. Variação (\%) } & 25,37 & \multicolumn{2}{|c|}{ C. Variação (\%) } & 20,83 & \multicolumn{2}{|c|}{ C. Variação (\%) } & 24,22 \\
\hline
\end{tabular}


No que se refere às instalações provisórias dos canteiros de obras, observa-se que os índices variaram de 8,82 (Obra 6) a 3,33 (Obra 7) pontos, com média de aproximadamente 7,14 pontos. Os canteiros das Obras 5, 7 e 9 obtiveram índices inferiores em relação ao índice médio para o grupo 1 (Instalações provisórias).

Já o canteiro da Obra 7 (menor índice no grupo 1), mal apresentava instalações. Não havia refeitório, vestiário, banheiros, nem sala técnica. Os funcionários dispunham apenas de um vaso sanitário dentro de uma instalação precária feita em madeirite. Não havia lavatórios para higienização das mãos, nem chuveiros para banhos. As refeições eram feitas ao sopé de árvores e as trocas de roupas eram feitas ou no interior da obra ou dentro do "banheiro".

$\mathrm{Na}$ Figura 2A está mostrado um bebedouro encontrado na obra 10 , que segue os parâmetros da norma regulamentadora do Ministério do Trabalho e Emprego número 18 (BRASIL, 2015) e na Figura 2B, o bebedouro da obra 7. Todos esses fatores justificaram a baixa nota obtida pela obra 7. No que se refere ao grupo 2 (Segurança na Obra), a média encontrada foi de 7,98 (Tabela 1). No entanto, houve uma variação muito grande entre as notas, foram encontrados valores entre 5,38 (Obra 7) e 10,00 (Obras 6 e 10).

A preocupação com a gestão de qualidade evidenciado no Grupo 1 por parte da Obra 6, também foi estendida para o Grupo 2, o que justifica a nota alcançada. Os itens de segurança eram constantemente testados e a equipe é frequentemente reciclada através de treinamentos e reuniões da Comissão Interna de Prevenção de Acidentes (CIPA). Por outro lado, pelo fato de a Obra 6 se tratar de uma obra vertical, a preocupação com a segurança torna-se de extrema importância, pois os riscos são maiores que em uma obra horizontal, já que é acrescentado o fator risco de queda de pessoas, materiais e equipamentos.

A obra 10 se destacou pela forte presença de sinalização de segurança em todos os locais do canteiro e da obra. Cada pavimento apresentava sinalização visual e indicação dos tipos de EPI's a serem utilizados para a atividade desenvolvida em cada pavimento. Quando não havia a existência de escada em concreto e fazia-se necessário o uso de escadas de madeira, estas eram bem afixadas às paredes e pisos, seguindo a recomendação da norma regulamentadora do Ministério do Trabalho e Emprego número 18 (BRASIL, 2015) de que as escadas que levam de um pavimento a outro superem em $1 \mathrm{~m}$ a altura do piso mais elevado. Todos os locais de possíveis quedas eram sinalizados e protegidos com telas, os buracos estavam protegidos e indicados com placas e, como diferencial, essa era a única obra que apresentava mapa de risco para as áreas comuns. Apesar de o check-list não contemplar o mapa de risco como item a ser verificado, o mapa é uma representação gráfica importante, pois evidencia um conjunto de fatores presentes nos locais de trabalho, capazes de acarretar prejuízos à saúde dos trabalhadores: acidentes e doenças de trabalho.

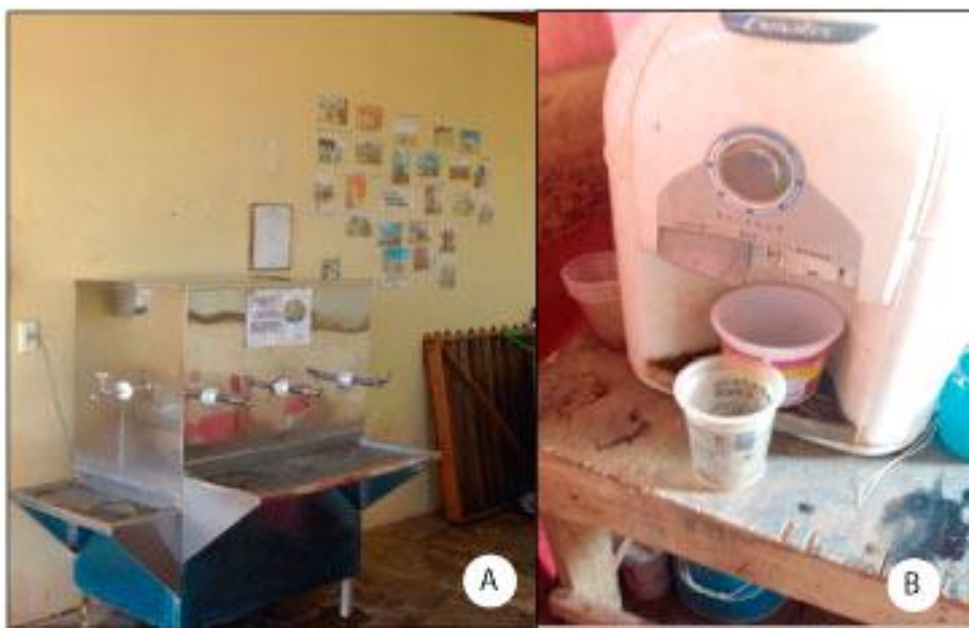

FIGURA 2: Elementos das instalações provisórias - [A] Bebedouro da obra 10 e [B] Bebedouro da Obra 7. FONTE: Os autores. 
Na obra 7 foi evidenciado mais uma vez a falta de atenção dos gestores, pois itens básicos como o uso de EPI's foram negligenciados. Apesar de haver treinamentos para os colaboradores, os mesmos não recebiam estímulo ou mesmo equipamentos de qualidade para uso. Por exemplo: os funcionários trabalhavam sem luvas, pois as luvas fornecidas pela empresa ao invés de proteger as mãos, estavam calejando, provocando feridas e machucados, fato este que desestimulava o uso de tal equipamento. As botas também estavam muito gastas e as fardas apresentavam remendos. Esse quadro explica a nota 5,38. Devido a uma questão ética e de política de anonimato das obras e construtoras analisadas, não houve registro fotográfico dos funcionários trabalhando nessas condições.

O Grupo 3 que corresponde à movimentação e armazenamento de materiais apresentou uma média dos índices de 6,90 pontos (Tabela 1). As obras 6 e 10 novamente obtiveram a mesma pontuação, que representou 0 valor máximo $(8,82)$ dentro do grupo 3 , enquanto a Obra 7 repetiu o desempenho ruim com o valor mínimo $(3,70)$. Conforme citado anteriormente, a Obra 10 dispunha de um canteiro amplo, e, portanto, dispunha de mais espaço para organização e disposição dos materiais. Os gestores utilizaram esse espaço para organizar melhor seu layout, definindo de maneira clara as locações das centrais de produção e dispondo os locais de armazenamento o mais próximo possível para a otimização dos trabalhos.

Na Obra 10 existe um almoxarifado para cada torre, uma das torres tinha inclusive mais de um almoxarifado. Os materiais eram acomodados em baias e era frequente o uso de pallets para que nenhum fosse disposto direto no solo. De fato, nenhum material foi visto acomodado de maneira errada. A nota atingida não foi a máxima devido ao duplo manuseio de areia e brita e a retirada do cimento, que não respeitava a ordem de entrada.

Durante a visita a campo, foi observado que a Obra 7 não apresentava nenhum local específico para destinação de materiais. Itens como areia e brita eram dispostos dentro da obra sem nenhuma proteção no solo ou contra chuva. Durante a visita, foi relatado que a maior parte do material só era enviada para obra em vésperas de utilização, devido justamente a essa falta de espaço para acomodação dos mesmos. As centrais eram rapidamente substituídas de acordo com as etapas da obra e alguns produtos, como armaduras para estruturas, eram fabricadas sob o sol, fazendo uso apenas de uma mesa para dobra, sem um ambiente adequado.

Na Figura 3 pode se relacionar os índices globais dos canteiros (média das notas dos grupos: instalações provisórias, segurança na obra e movimentação e armazenamento de materiais) com o tipo de cada obra e verificar a diferença entre canteiros de obras horizontais e verticais. Enquanto os canteiros horizontais obtiveram notas globais baixas, variando entre 4 e 6 pontos, os canteiros verticais apresentaram notas mais elevadas, todas as obras acima de 7 pontos.

Possivelmente, um dos fatores que mais influência nessa diferença de desempenho entre canteiros verticais e horizontais é o fator espaço. Usualmente a área disponível para o canteiro de uma construção horizontal é a mesma área que virá ser a construção. Gerando a necessidade de desfazer itens do canteiro à medida que a obra avança. A ausência de alguns desses itens pode contribuir para a redução da nota bem como a falta de acomodação adequada para estoque dos materiais de construção.

Observa-se pela Figura 3 que as obras verticais em variados estágios de execução, desde fundações até acabamentos, não houve influência significativa na qualidade global dos canteiros da região, tendo em vista que todos mantiveram-se com índices elevados (acima de 7). O mesmo comportamento é evidenciado nos canteiros de obras horizontais que mantiveram pequena variação de índice global (apenas 1 ponto), para obras em diferentes estágios de execução: vedações (Obra 5), acabamentos (Obra 7) e pisos e coberturas (Obra 9). Isto indica que para o fator estágio de execução os canteiros de obra da região Crajubar praticamente não variam em relação a organização global. 


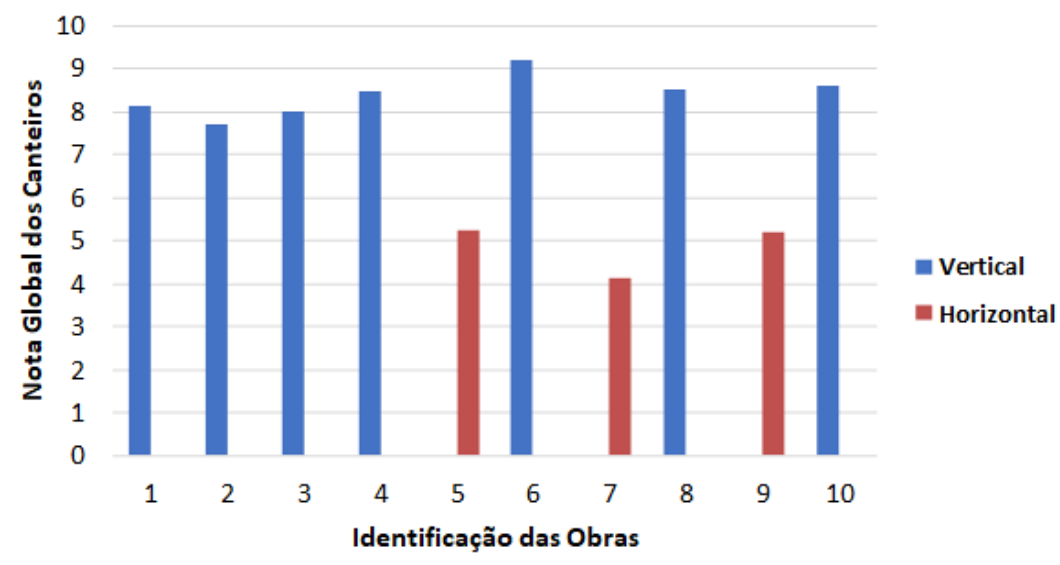

FIGURA 3: Índices Globais dos canteiros de obras.

FONTE: Os autores.

Nota-se também que em relação as diferentes empresas construtoras das obras, tanto para obras verticais como horizontais, não houve uma variação considerável entre as notas globais dos canteiros da região. Estes resultados demonstram que, possivelmente, o padrão construtivo entre as obras verticais e horizontais foi o motivo para a discrepância verificada entre as mesmas.

As variações dos índices globais em relação aos índices de grupos podem ser observadas na Figura 4. Não houve grande variação entre os índices de grupo para cada obra. É possível observar que as obra cujo índice foi elevado no G1 (instalações provisórias), também mantém o bom desempenho no G2 (segurança na obra) e no G3 (sistema de movimentação e armazenamento de materiais), o que gera uma boa pontuação no índice global, uma vez que esta é a média aritmética das demais. Da mesma forma acontece com obras que apresentaram um baixo desempenho.

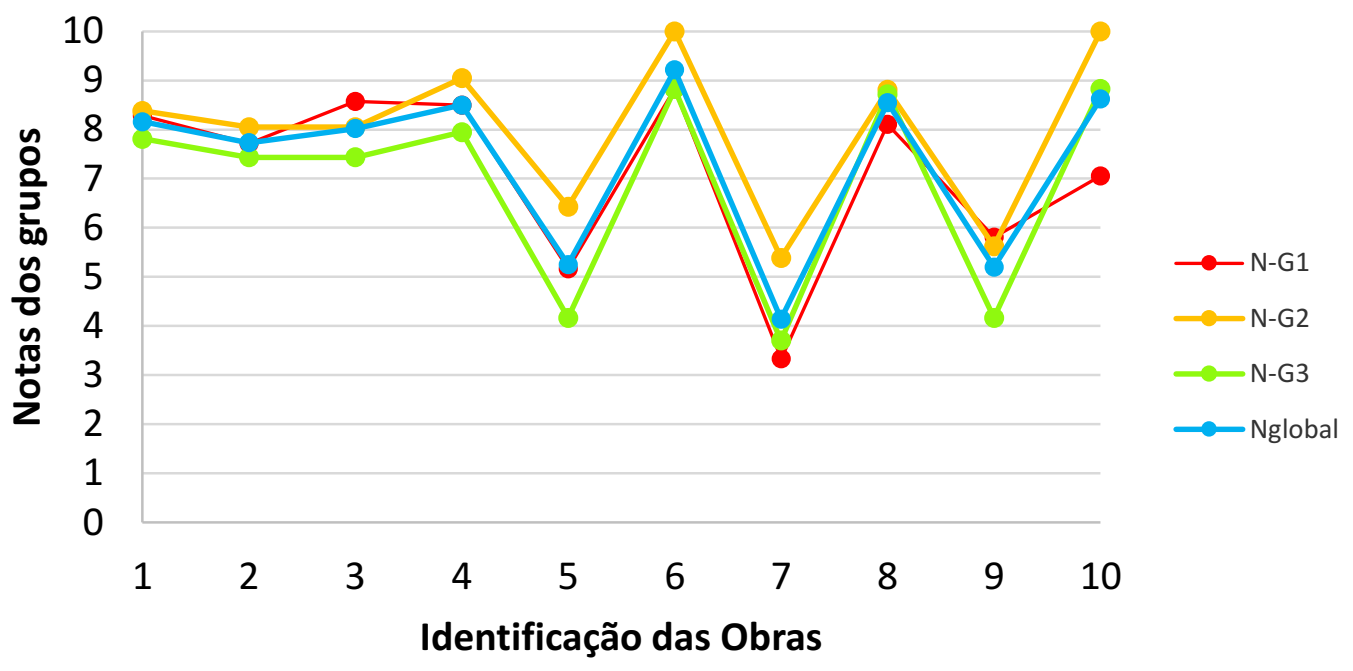

FIGURA 4: Notas de Grupo de cada Obra.

FONTE: Os autores. 
A classificação de cada canteiro das obras estudados de acordo com o sistema de classificação do Ministério do Trabalho e Emprego (BRASIL, 2003) está apresentada na Tabela 2. Nota-se que $50 \%$ dos canteiros obtiveram classificação "Ótimo" no grupo de Instalações provisórias. Todos esses canteiros eram de obras verticais. Houve apenas uma classificação "Ruim", da obra 7, o que reforça a discussão já feita acerca das instalações dessa obra, sendo verificado a necessidade de interrupção da obra até sua regularização.

Sobre a segurança na obra, os índices classificados como "Ótimo" corresponderam a 70\%, justamente os canteiros de obras verticais e os $30 \%$ restante correspondem aos canteiros de obras horizontais. No entanto, vale ressaltar que mesmo entre os canteiros de obras horizontais, não houve nenhum classificado como "Péssimo". Apesar das falhas encontradas, as condições de segurança nos canteiros ainda se mantêm regular. Quanto ao grupo 3 (Movimentação e Armazenamento de Materiais), foi o que apresentou menor percentual de canteiros "Ótimos", apenas 30\%. Nota-se que para este grupo a Obra 7 também se configurou como ruim, indicando também necessidade de paralização da construção até regularização de seus procedimentos.

O grupo de segurança na obra pode ter apresentado melhores índices nas obras da região, devido a maior atenção por profissionais específicos como o(a) engenheiro(a) de segurança
Do trabalho e o técnico de segurança do trabalho. Além disto, as fiscalizações dos itens desse grupo pelos os órgãos competentes são mais frequentes, refletindo assim nas melhores notas de segurança na obra dos canteiros da região.

Para análise dos resultados globais quanto à classificação do ministério do trabalho e emprego (BRASIL, 2003), a partir da Figura 5 é possível identificar a quantidade de obras que se enquadra em cada faixa de classificação (entre ótimo e ruim). Observa-se que $60 \%$ das obras visitadas apresentaram uma classificação ótima, quando levado em consideração os três grupos, e nenhuma obra foi classificada como ruim. Mesmo com as falhas apresentadas em todos os canteiros, a preocupação com a gestão de qualidade, com a segurança na obra, com o aumento da produtividade e práticas adotadas por todas as construtoras, mesmo as pequenas, fez com que as notas quando ponderadas utilizando-se todas as informações possíveis culminaram em uma boa avaliação na maior parte dos casos estudados. Isso mostra a importância da avaliação dos canteiros de obras de forma mais detalhada por grupo, tendo em vista o exemplo da Obra 7 que ao ser avaliada pela nota global apresenta-se como regular, porém ao ser avaliada por grupo apresenta-se como ruim, isto é, em desacordo com as normas regulamentadoras do trabalho, no que se refere as instalações provisórias e movimentação e armazenamento de materiais.

TABELA 2: Classificação das obras pelos índices de grupos de acordo com o Brasil (2003)

\begin{tabular}{ccccccc} 
Obra & G1 & Classificação & G2 & Classificação & G3 & Classificação \\
\hline 1 & 8,29 & Ótimo & 8,38 & Ótimo & 7,81 & Bom \\
2 & 7,71 & Bom & 8,05 & Ótimo & 7,44 & Bom \\
3 & 8,57 & Ótimo & 8,05 & Ótimo & 7,44 & Bom \\
4 & 8,5 & Ótimo & 9,05 & Ótimo & 7,95 & Bom \\
5 & 5,16 & Regular & 6,43 & Bom & 4,17 & Regular \\
6 & 8,82 & Ótimo & 10 & Ótimo & 8,82 & Ótimo \\
7 & 3,33 & Ruim & 5,38 & Regular & 3,7 & Ruim \\
8 & 8,11 & Ótimo & 8,81 & Ótimo & 8,72 & Ótimo \\
9 & 5,81 & Regular & 5,63 & Regular & 4,17 & Regular \\
10 & 7,06 & Bom & 10 & Ótimo & 8,82 & Ótimo \\
\hline \multicolumn{7}{c}{}
\end{tabular}




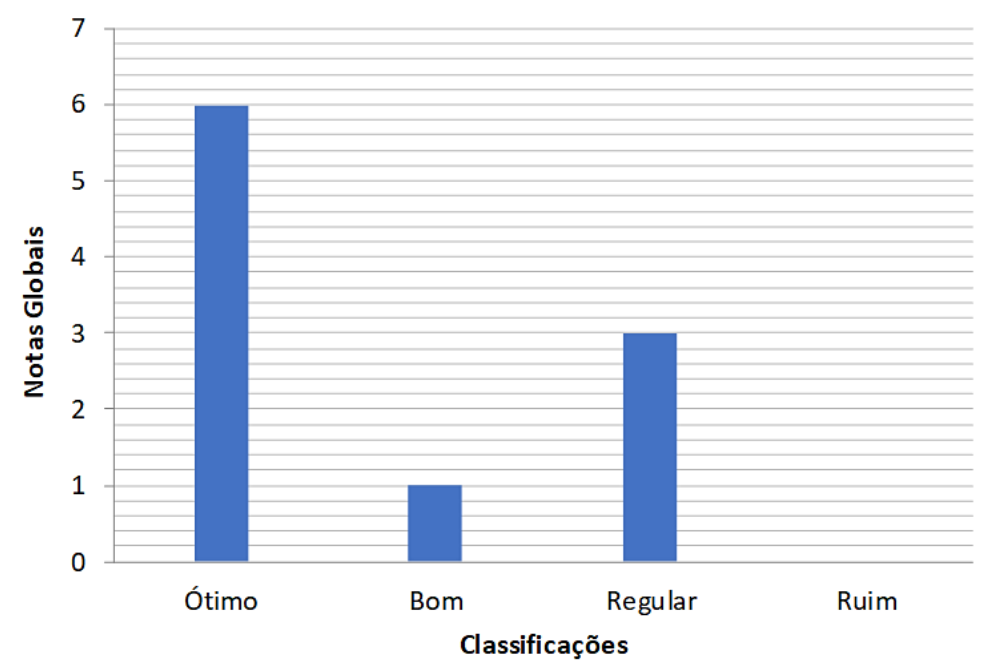

FIGURA 5: Quantidade de obras de acordo com a classificação das notas.

FONTE: Os autores.

Quando comparada a situação dos canteiros de obra da região do Crajubar com outras regiões, onde foi aplicada a mesma metodologia proposta por Saurin e Formoso (2006), pode-se observar a falta de conhecimento bem como a falta de busca pela melhoria nos canteiros de obras analisados. Estudos como o de Herman, Langaro e Siliprandi (2012) mostram que cidades como Recife ou mesmo estados como Rio Grande do Sul ainda têm grandes dificuldades no arranjo de seus canteiros.

Desde o ano de 1996, quando foi proposta a metodologia de Saurin e Formoso (2006) pela primeira vez, que há a aplicação do check-list e avaliação de obras no Rio Grande do Sul (HERMAN, LANGARO e SILIPRANDI, 2012). Apesar disso, os autores afirmam que as melhorias que são obtidas em um canteiro ainda não conseguem ser estendidas para outros, perdurando a presença de muita improvisação e falta de padronização.

Estudos similares também foram realizados em Angicos no estado do Rio Grande do Norte por Ribeiro (2011). O autor identificou que a maioria dos canteiros não tinham uma instalação adequada para eles, sendo em sua maioria dispostos em calçadas ou vias públicas da cidade, mesmo quando havia espaço disponível na obra para instalação dos mesmos. Fato não observado nas obras visitadas no Crajubar.

Ainda em Angicos foi notada a ausência de itens de segurança. Segundo Ribeiro (2011) não eram fornecidos EPI's pelas empresas e os canteiros não dispunham de alojamentos, vestiários ou mesmo instalações sanitárias. $\mathrm{O}$ armazenamento de materiais também era negligenciado, bem como seu transporte.

A obra 7 apontada neste trabalho como a pior, em termos de instalações provisórias, segurança na obra e movimentação e armazenamento de materiais seria facilmente enquadrada com o comportamento similar a situação observada na cidade de Angicos.

\section{CONSIDERAÇÕES FINAIS}

O tipo de obra foi um dos fatores que mais afetou a qualidade dos canteiros do Crajubar, sendo encontradas melhores condições de trabalho, organização e menores perdas de recursos nos canteiros de obras verticais. $O$ padrão construtivo de cada tipo de obra pode ter contribuído para a grande disparidade entre as 
obras verticais e horizontais. O estágio de execução da obra e as empresas construtoras não apresentaram grande influência nas notas dos canteiros de obras da região do Crajubar.

A saúde ocupacional e a segurança no trabalho por ser uma área mais normatizada, sobretudo as normas regulamentadoras do Ministério do Trabalho e Emprego, foi o item que apresentou menores falhas na maioria dos canteiros analisados do Crajubar. No entanto, como sugestão de implementação do questionário utilizado nesta pesquisa sugere-se a inclusão da verificação no grupo de segurança na obra dos itens relacionados ao mapa de risco e a comissão interna de prevenção de acidentes.

A movimentação e armazenamento de materiais foi o grupo onde foram encontradas mais falhas e inconformidades nos canteiros da região Crajubar. A concepção das baias e a logística de movimentação dos materiais em canteiros com áreas restritas, como as obras horizontais, foram os principais fatores que influenciaram neste grupo.

A Obra 7 foi a única que apresentou canteiro diagnosticado com falhas graves na região, sendo necessário a interrupção de sua operacionalização até as devidas alterações serem implementadas. Embora a avaliação global não tenha apresentado canteiros de obras classificados "Ruim", a avaliação por grupo identificou está classificação na obra 7 para instalações provisórias e movimentação e armazenamento de materiais, destacando assim a importância de avaliar cada setor do canteiro por grupo e não apenas de forma generalizada.

\section{REFERÊNCIAS BIBLIOGRÁFICAS}

BRASIL, Ministério do Trabalho. Programa de Avaliações das Condições de Trabalho da Indústria da Construção Civil. Metodologia Aplicada - Check-List. Jundiaí - SP, 2003. Disponível em: http://www.fiocruz.br/biosseguranca/Bis/manuais/con strucao\%20civil/Programa\%20de\%20Avaliacao\%20das \%20Condicoes\%20de\%20Trabalho\%20da\%20Industria\% 20da\%20Construcao\%20Civil.pdf. Acesso em: 24/08/2016.
BRASIL, Ministério do Trabalho e Emprego. NR 18: condições e meio ambiente de trabalho na indústria da construção. Brasília, DF, 2015. Disponível em: http://trabalho.gov.br/data/files/FF8080814CD7273D0 14D350CBF47016D/NR-

18\%20(atualizada\%202015)limpa.pdf . Acesso em: 30 de julho de 2016.

FORMOSO, C. T.; SOIBELMAN, L.; CESARE, C. de. ISATTO, E. L. Material waste in building industry: Main causes and Prevention. Journal of Construction Engineering and Management, v. 128, n.4, p. 316-325, 2002.

GURGEL, A. P. C. Entre serras e sertões nasce uma região metropolitana: o Crajubar-Ceará sob o ponto de vista de suas centralidades. DRd-Desenvolvimento Regional em debate, v. 2, n. 2, p. 182-204, 2012 DOI: http://dx.doi.org/10.24302/drd.v2i2.274.

HERMANN,A.; LANGARO, E. A.; SILIPRANDI, E. M. Planejamento estratégico do canteiro de obras como uma vantagem técnica e econômica no mercado da construção civil. In: XVII SICITE - Seminário de Iniciação Científica e Tecnológica da UTFPR, Curitiba - PR, 2012.

IBGE (2015a). Perfil Econômico e infográficos da cidade de Barbalha. Disponível em: http://cod.ibge.gov.br/2A6 . Acesso em: 01 de novembro de 2015.

IBGE (2015b) Perfil Econômico e infográficos da cidade do Crato. Disponível em: http://cod.ibge.gov.br/2JYLO. Acessado em: 01 de novembro de 2015.

IBGE (2015c) Perfil Econômico e infográficos da cidade de Juazeiro do Norte. Disponível em: http://cod.ibge.gov.br/234FL. Acessado em: 01/11/2015.

LIMA JÚNIOR, F. O. de; MORAIS, J. M. L. Industrialização e políticas públicas: a dinâmica do desenvolvimento nos municípios do triângulo Crajubar cearense (Crato, Juazeiro do Norte e Barbalha). Interface, v. 6, n.2, 2009.

MAGALHÃES, R. F. de; DANILEVICZ, A. de M. F.; SAURIN, T. A. Reducing construction waste: A study of urban infrastructure projects. Waste Management, v. 67, p 265-277, 2017.2 DOI: https://doi.org/10.1016/j.wasman.2017.05.025.

MARANHÃO, Mauriti. ISO SERIE 9000-VERSAO 2000. Qualitymark Editora Ltda, 1993.

MATTANA, L.; LIBRELOTTO, L. I. Contribuição do BIM para a sustentabilidade econômica de edificações. MIX Sustentável, v. 3, n. 2, p. 135-147, 2017.

NUNES, K. R. A.; MAHLER, C. F.; VALLE, R. A. Reverse logistics in the Brazilian construction industry. Journal of environmental management, v. 90, n. 12, p. 3717-3720, 2009. DOI: 10.1016/j.jenvman.2008.05.026. 
RIBEIRO, P. F. C. Caracterização dos canteiros de obra da cidade de Angicos/RN. Universidade Federal Rural do Semi-Árido. Angicos, Rio Grande do Norte. 2011. Monografia (Graduação em Ciência e Tecnologia).

RODRIGUES, C. P. B.; ALVES, D. F.; SANTOS, M. D. C. dos; SANTOS, J. M. Desenvolvimento sustentável e turismo no espaço rural: Uma perspectiva exploratória no triângulo Crajubar. Ciência e Sustentabilidade, v. 2, n. 1, p. 82-102, 2016.

SANTOS, C. A. do; LIMA JÚNIOR, F. O de. Transformações econômicas e avanço na polarização na mesorregião sul cearense. In: VI Seminário Internacional sobre Desenvolvimento Regional, Santa Cruz do Sul -RS, 2013.

SAURIN, T. A.; FORMOSO, C. T. Planejamento de Canteiros de Obra e Gestão de Processos. Recomendações Técnicas Habitare. Vol. 3. Porto Alegre. 2006. Disponível em: http://cursos.unisanta.br/civil/arquivos/capítulos_rt_3vol3-habitare.pdf. Acessado em: 01/11/2015.

SCHRAMM, F. K.; FORMOSO, C. T. Projeto de sistemas de produção na construção civil empregando simulação no apoio à tomada de decisão. Ambiente Construído (Online), v. 15 , p. 165-182, $2015 . \quad$ DOI: http://dx.doi.org/10.1590/s1678-86212015000400045.

SOUZA, U. E. L.; AGOPYAN, V.; PALIARI, J. C. Desperdício - Conhecendo as perdas de materiais na construção. Qualidade na construção, São Paulo, n.20, p.34, 1999. 